\title{
Synthesis of diamido-bridged bis-pillar[5]arenes and tris-pillar[5]arenes for construction of unique [1]rotaxanes and bis-[1]rotaxanes
}

\author{
Ying Han, Li-Ming Xu, Cui-Yun Nie, Shuo Jiang, Jing Sun and Chao-Guo Yan*
}

\author{
Full Research Paper \\ Address: \\ College of Chemistry \& Chemical Engineering, Yangzhou University, \\ Yangzhou 225002, P. R. China \\ Email: \\ Chao-Guo Yan* - cgyan@yzu.edu.cn \\ * Corresponding author \\ Keywords: \\ bis-[1]rotaxane; mechanically interlocked molecule; pillar[5]arene; \\ [1]rotaxane; self-assembly
}

\author{
Beilstein J. Org. Chem. 2018, 14, 1660-1667. \\ doi:10.3762/bjoc. 14.142 \\ Received: 17 April 2018 \\ Accepted: 20 June 2018 \\ Published: 04 July 2018 \\ This article is part of the thematic issue "Macrocyclic and supramolecular \\ chemistry". \\ Guest Editor: M.-X. Wang
}

(C) 2018 Han et al.; licensee Beilstein-Institut.

License and terms: see end of document.

\begin{abstract}
The pillar[5]arene mono- and di(oxyalkoxy)benzoic acids were successfully prepared in high yields by sequential alkylation of $\omega$-bromoalkoxy-substituted pillar[5]arenes with methyl or ethyl $p$-hydroxybenzoate followed by a hydrolytic reaction under basic conditions. Under catalysis of $\mathrm{HOBt} / \mathrm{EDCl}$, the amidation reaction of pillar[5] arene mono(oxybutoxy)benzoic acid with monoamido-functionalized pillar[5] arenes afforded diamido-bridged bis-pillar[5]arenes. ${ }^{1} \mathrm{H}$ NMR and 2D NOESY spectra clearly indicated that [1] rotaxanes were formed by insertion of longer diaminoalkylene unit into the cavity of one pillar[5] arene with another pillar[5]arene acting as a stopper. The similar catalysed amidation reaction of pillar[5]arene di(oxybutoxy)benzoic acid with monoamido-functionalized pillar[5] arenes resulted in the diamido-bridged tris-pillar[5]arenes, which successfully form the unique bis-[1] rotaxanes bearing longer than diaminopropylene diamido bridges.
\end{abstract}

\section{Introduction}

The construction and dynamic motion of the mechanically interlocked molecules (MIMs) have attracted significant research interests due to their intrinsic self-assembled nature and potential applications in various aspects [1-4]. Pseudo[1]rotaxane and [1] rotaxane are one of particular supramolecular assembly system and are considered as an important building block in the construction of diverse MIMs [5-10]. [1]Rotaxane has a macro- cyclic wheel component connected with a self-locked chain axle, and a bulky stopper at the terminal axle to prevent dissociation of the subcomponents. In recent years, many effects have been devoted to the construction and functionalization of pseudo[1]rotaxanes and [1]rotaxanes [11-20]. For this purpose, the well-known macrocycles such as crown ether [21-23], cyclodextrin [24-26], calixarene [27-29] and pillararene have 
been successfully employed as the wheel subcomponent. Pillararenes are new star macrocyclic compounds with aromatic rings para-bridged by methylene units and have unique tubular shape rather than cone [30-32]. In recent years, an explosive development on the construction of various supramolecular devices and diverse responsive materials has been reported by using diverse functionalized pillararenes [33-35]. Due to easily preparation and suitable cavity, functionalized pillar[5]arenes were widely used as wheel component for constructing of the various interlocked molecules [36-42]. In the past few years, many elegant works on the construction of pseudo[1]rotaxanes and [1]rotaxanes have been developed on the basis of various mono-functionalized pillar[5]arenes [43-57]. Recently, we have successfully constructed a couple of pseudo[1]rotaxane and [1]rotaxane both in solution and in solid state developed by using mono-functionalized pillar[5] arene Schiff base, urea and pyridylimine derivatives [58-63]. In continuation of our effort on the development on the construction of [1] rotaxanes via various mono-functionalized pillar[5]arene derivatives, herein we wish to report the convenient synthesis of diamido-bridged bis-pillar[5]arenes and trispillar[5]arenes as well as formation of unique [1] rotaxanes and bis-[1]rotaxanes.

\section{Results and Discussion}

The synthetic route for the pillar[5]arene mono(oxyalkoxy)benzoic acids was illustrated in Scheme 1. Firstly, the alkylation of mono(bromoalkoxy)pillar[5] arene 1a-c $(n=4,5,6)$ [64] with methyl or ethyl $p$-hydroxybenzoate was carried out in the refluxed medium of $\mathrm{KI} / \mathrm{K}_{2} \mathrm{CO}_{3} / \mathrm{CH}_{3} \mathrm{CN}$ for one day. The pillar[5]arene mono(oxyalkoxy)benzoates $\mathbf{2 a}-\mathbf{f}$ were successfully prepared in high yields. Then, basic hydrolysis of pillar[5] arene mono(oxyalkoxy)benzoates $\mathbf{2 a - f}$ in ethanol in the presence of potassium hydroxide afforded the desired pillar[5]arene mono(oxyalkoxy)benzoic acids 3a-c. The structures of the prepared pillar[5]arenes $\mathbf{2 a}-\mathbf{f}$ and $\mathbf{3 a}-\mathbf{c}$ were fully characterized by the spectroscopic methods. The single crystal structures of the pillar[5] arenes $\mathbf{2 a}$ (Figure 1), 2c, 2d, 2e (Supporting Information File 1, Figure S1-S3) and $2 \mathbf{f}$ (Figure 2) were successfully determined by X-ray diffraction. The same structural feature was obtained in the five single crystals. That is, the longer chain of methyl (ethyl) oxyalkoxybenzoate not only does not inserted in the cavity of the pillar[5]arene to form the pseudo[1]rotaxane, but also does not thread to the cavity of the neighbouring pillar[5] arene to form the supramolecular polymer. This result is consistent to the Cao's previously reported results in the series of pillar[5]arenes bearing aliphatic esters [49], in that they found the chain of methyl oxybutyrate did not threaded into the cavity of pillar[5]arene.

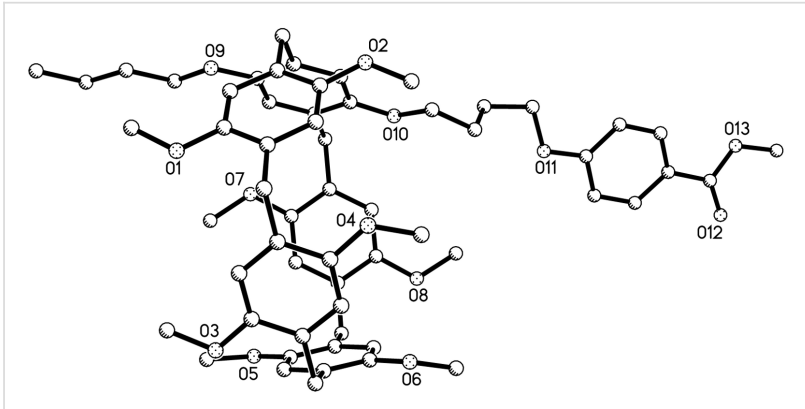

Figure 1: single crystal structure of pillar[5]arene $\mathbf{2 a}$.

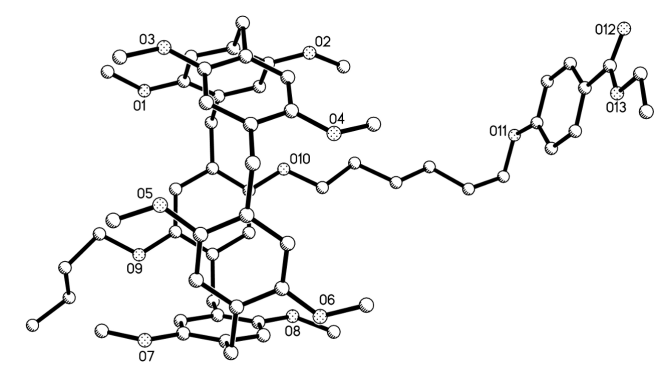

Figure 2: Single crystal structure of pillar[5]arene $\mathbf{2 f}$.

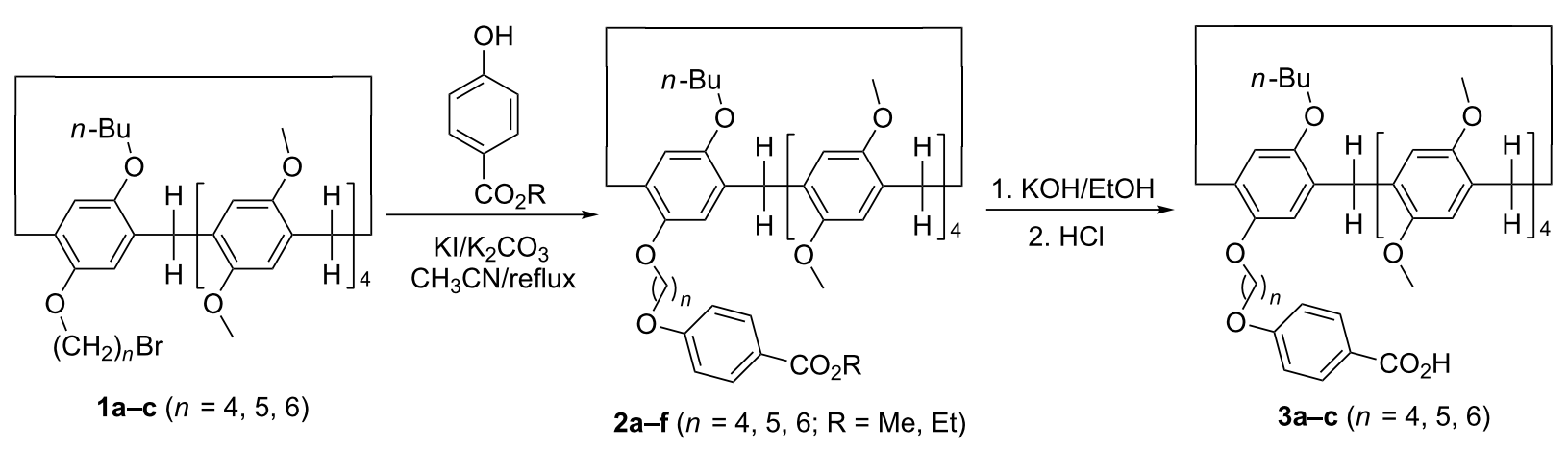

Scheme 1: Synthesis of pillar[5]arene mono(oxyalkoxy)benzoic acids 3a-c. 
The above synthetic pillar[5] arene mono(oxyalkoxy)benzoic acids have a longer chain functionalized group and a large macrocycle, which enabled them to be a good candidate as an efficient terminal stopper for the construction of rotaxanes. Therefore, the amidation reaction of pillar[5]arene mono(oxybutoxy)benzoic acid 3a with our previously reported amidofunctionalized pillar[5] arenes $\mathbf{4 a}-\mathbf{d}(n=2,3,4,6)$ [58] was carried out in chloroform under the combined catalysis of 1-hydroxybenzotrizole (HOBt) and 1-(3-dimethylaminopropyl)3 -ethylcarbodiimide hydrochloride (EDCl). The reaction proceeded smoothly to give diamido-bridged bis-pillar[5]arenes 5a-d $(n=2,3,4,6)$ in moderate yields (Scheme 2$)$. It has been reported that the chain of $N$-( $\omega$-aminoalkyl)oxyacetamide inserted in the cavity of pillar[5]arene in the amido-functionalized pillar[5]arene $4 \mathbf{a}-\mathbf{d}(n=2,3,4,6)$ to form pseudo[1]rotaxanes both in solution and in solid state [58]. The diamidobridged bis-pillar[5]arenes $\mathbf{5 a}-\mathbf{d}$ might form the expected [1]rotaxanes. ${ }^{1} \mathrm{H}$ NMR spectrum of the bis-pillar[5] arenes 5a clearly showed that there is no any signals at very high magnetic field $(\delta<0)$, which indicated that the diaminoethylene chain does not inserted in the cavity of pillar[5]arene to form the expected [1] rotaxane. Therefore, the two moieties of pillar[5]arenes are just connected by the diaminoethylene chain from the outside in diamido-bridged bis-pillar[5] arenes 5a. However, a couple of characteristic signals at very high magnetic field can be seen in the ${ }^{1} \mathrm{H}$ NMR spectra of the bispillar[5]arenes $\mathbf{5 b}-\mathbf{d}$. There is a broad singlet at $-1.82 \mathrm{ppm}$ in $\mathbf{5 b}$, a mixed peak at -1.88 to $-2.14 \mathrm{ppm}$ in $\mathbf{5} \mathbf{c}$ and several peaks in the range of 0.07 to $-2.07 \mathrm{ppm}$ in $\mathbf{5 d}$. This result clearly displayed that the unique [1]rotaxane structures were actually formed by threading the longer diaminoalkylene bridge in the cavity of one molecular pillar[5]arene, while another pillar[5]arene as the bigger stopper. Additionally, 2D NOESY spectra of the compound 5d provided more strong evidence for the formation of [1] rotaxane (Figure 3). The NOE correlations were clearly observed between $\mathrm{Ha}, \mathrm{Hb}, \mathrm{Hc}, \mathrm{Hd}$, and $\mathrm{He}$ protons of the bridging hexylene chain with the proton $\mathrm{Hf}$ in the core of pillar[5] arene. The proton $\mathrm{Hb}$ of the bridging hexylene chain also correlated with protons of the aromatic protons $\mathrm{Hg}$ and Hf.

According to similar reaction procedure for the synthesis of pillar[5] arene mono(oxyalkoxy)benzoic acids $\mathbf{3 a - c}$, pillar[5] arene di(oxybutoxy)benzoic acid $\mathbf{8}$ was prepared in moderate yield from sequential alkylation and basic hydrolysis reaction (Scheme 3 ). The single crystal structure of the

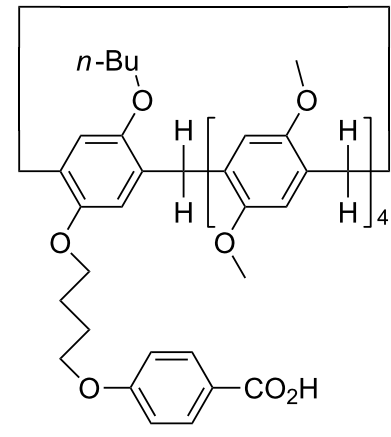

$3 a$

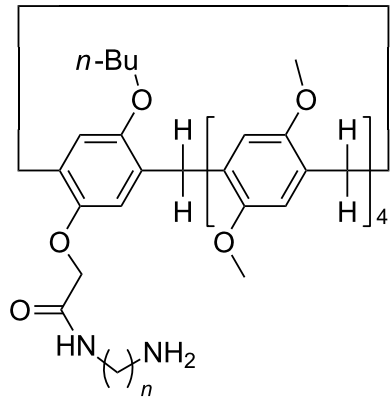

4a-d $(n=2,3,4,6)$

\section{HOBt/EDCl $\downarrow \mathrm{CHCl}_{3}$}

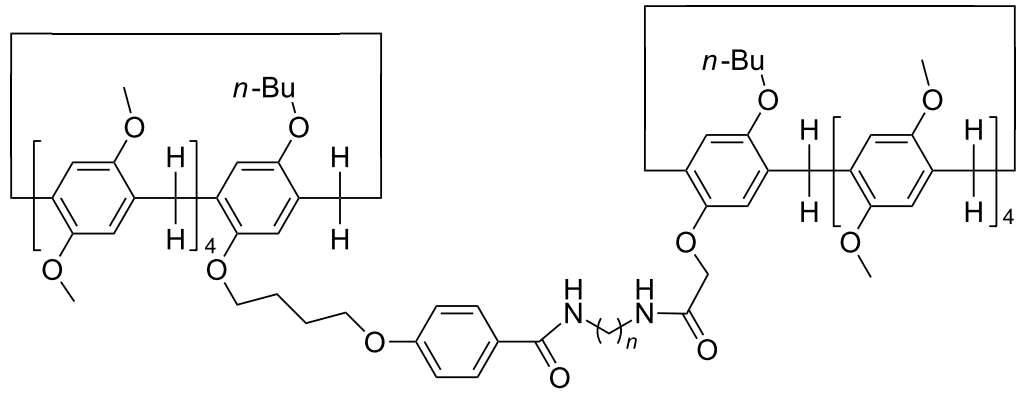

$\mathbf{5 a}-\mathbf{d}(n=2,3,4,6)$ 


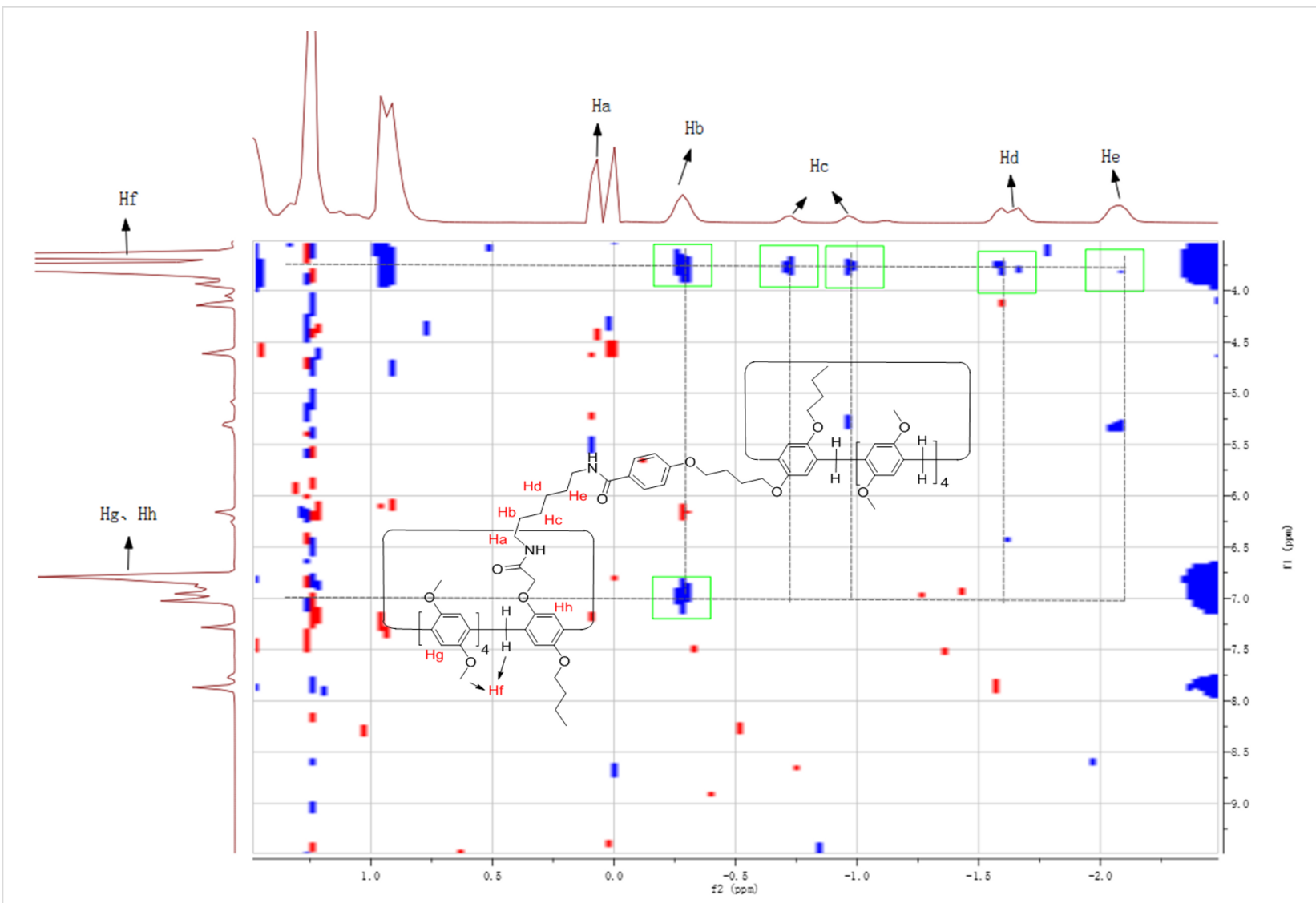

Figure 3: The 2D NOSEY spectrum of bis-pillar[5]arene $\mathbf{5 d}$.

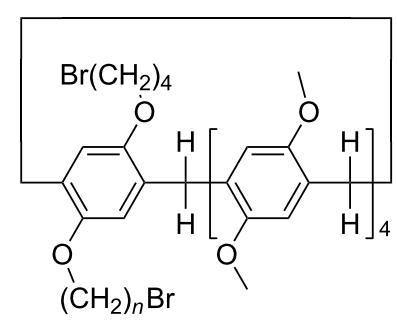

6

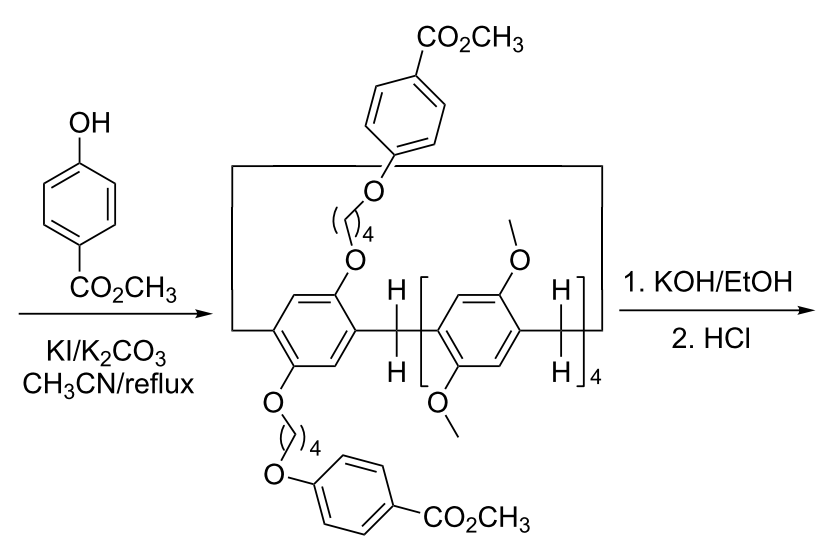

7

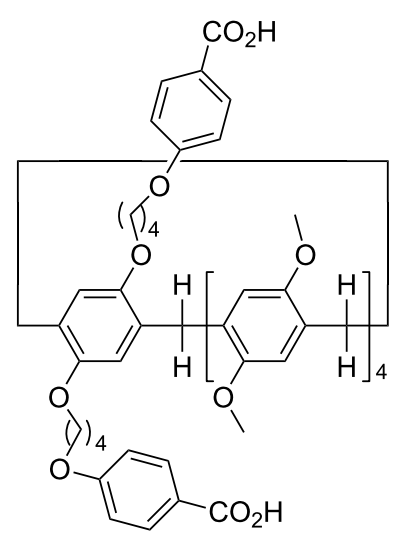

8

Scheme 3: Synthesis of pillar[5]arene di(oxyalkoxy)benzoic acid 8.

pillar[5]arene di(oxybutoxy)benzoate 7 showed that the two chains of methyl oxybutoxybenzoate did not insert in the cavity of pillar[5]arene (Figure 4) as that of the above mentioned pillar[5] arene mono(oxybutoxy)benzoates $\mathbf{2 a - f}$. The two chains straight stretched to the opposite direction of central pillar[5]arene. It might be attribute to the electron-rich effect of the methyl oxybutoxybenzoate unit, which kept it away from the electron-rich cavity of pillar[5]arene.

Under the combined catalysis of HOBT and EDCl, the amide reaction of pillar[5]arene di(oxybutoxy)benzoic acid 8a with two molecular amido-functionalized pillar[5] arenes $\mathbf{4 a - d}$ in 


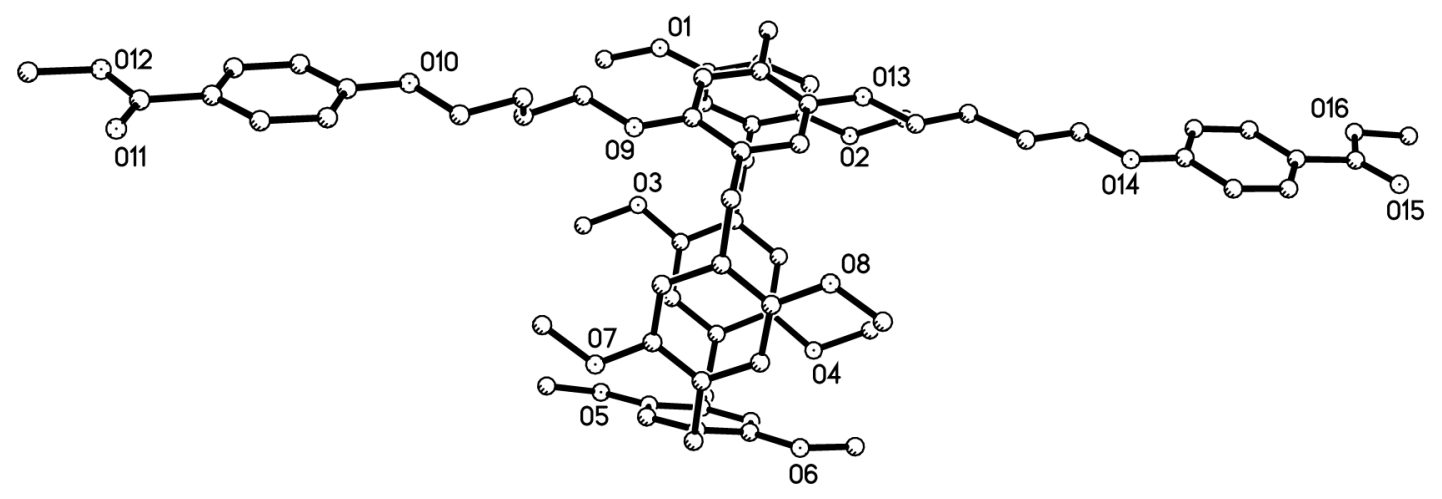

Figure 4: Single crystal structure of pillar[5]arene 7.

chloroform afforded tris-pillar[5]arenes 9a-d in moderate yields (Scheme 4). The structures of the synthetic tris-pillar[5]arenes 9a-d were fully characterized by IR, HRMS, ${ }^{1} \mathrm{H}$ and ${ }^{13} \mathrm{C} \mathrm{NMR}$ spectra. The ${ }^{1} \mathrm{H}$ NMR spectra provided stronger evidence for the formation of fascinating bis-[1]rotaxanes. Because there are no peaks with negative chemical shift in the ${ }^{1} \mathrm{H}$ NMR spectra of the tris-pillar[5]arene 9a, it can be concluded that the three pillar[5]arenes are connected from the outsides by two diamidoethylene-bridges. There is one broad peak at $-1.80 \mathrm{ppm}$ in trispillar[5]arene 9b, a mixed peak at $-2.00 \mathrm{ppm}$ in trispillar[5]arene 9c, and five broad peaks at $-0.29 \mathrm{ppm}$, $-0.74 \mathrm{ppm},-0.97 \mathrm{ppm},-1.62 \mathrm{ppm}$ and $-2.08 \mathrm{ppm}$ in trispillar[5] arene 9d. Therefore, ${ }^{1} \mathrm{H}$ NMR spectra of $9 \mathbf{b}-\mathbf{d}$ indicated that the diaminoalkylene chain ambiguously inserted in the

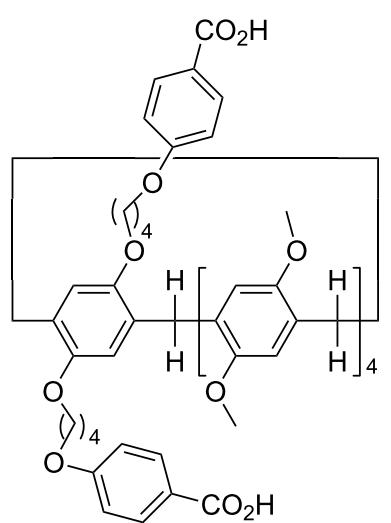

8

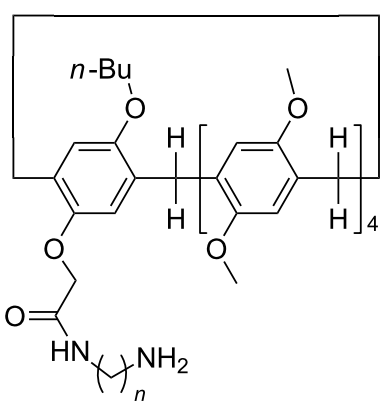

4a-d $(n=2,3,4,6)$

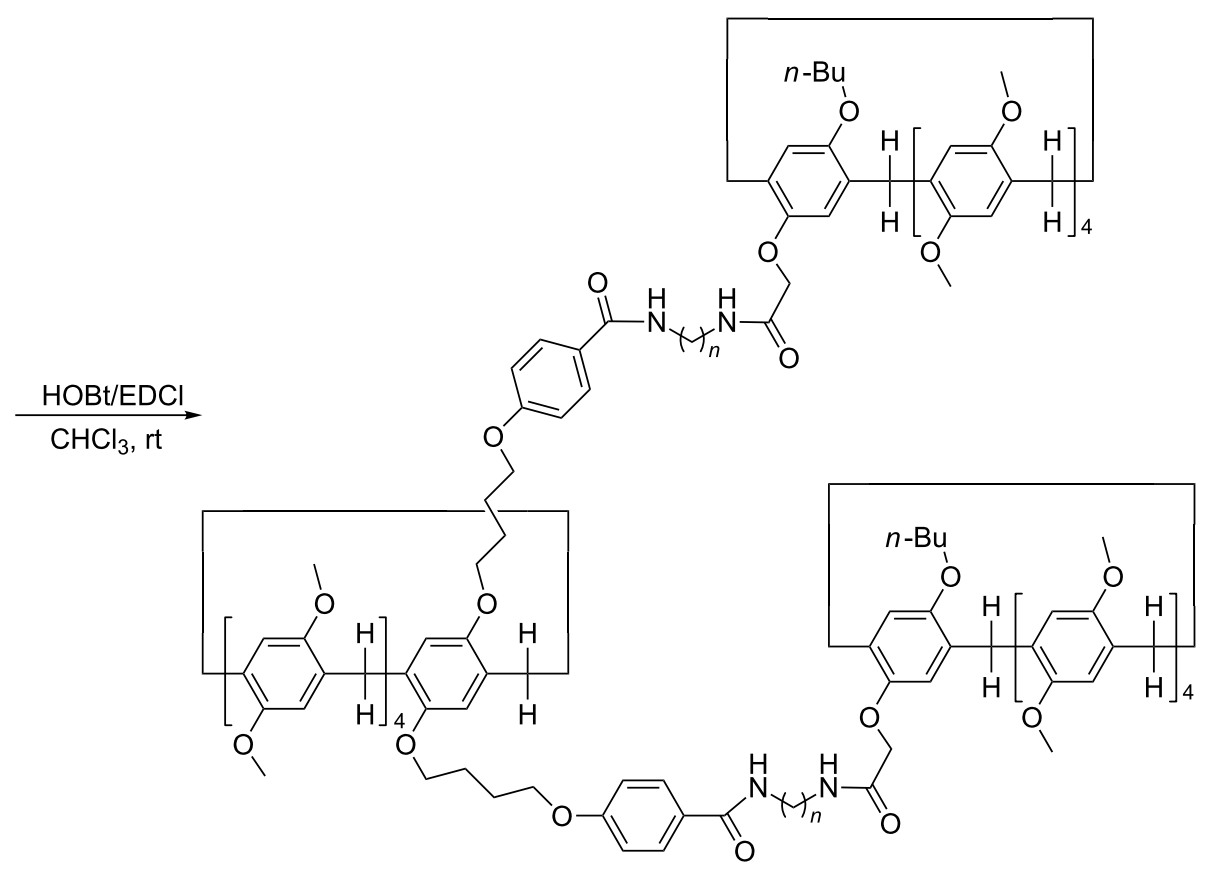

$\mathbf{9 a}-\mathbf{d}(n=2,3,4,6)$ 
cavity of the pillar[5]arene. In other words, the fascinating bis[1] rotaxane structures were formed in the tris-pillar[5]arenes 9b-d. Here, the lengths of bridging chains played the critical role in the selflocked behaviour of pillar[5]arene-based [1]rotaxanes.

In order to confirm the formation of the bis-[1]rotaxanes, 2D NOESY spectra of the compounds $9 \mathbf{a}-\mathbf{d}$ were recorded. The 2D NOESY spectrum of compound 9d was showed in Figure 5. There it can be seen that the NOE correlations were clearly observed between $\mathrm{Ha}, \mathrm{Hb}, \mathrm{Hc}, \mathrm{Hd}, \mathrm{Hf}, \mathrm{Hg}$, Hh protons of the bridging diaminohexylene chain and the protons $\mathrm{Hi}, \mathrm{Hj}$ in the core of pillar[5]arene. Additionally, some correlations exists between protons $\mathrm{Ha}, \mathrm{He}, \mathrm{Hd}$ and $\mathrm{Hh}$ and active amino $(\mathrm{N}-\mathrm{H})$ group. These NOE correlations clearly indicated the two bridged diaminohexylene chain threading into the cavity of the two pillar[5]arenes to form the bis-[1] rotaxane. The similar correlations were also observed in the NOESY spectra of the tris-pillar[5] arene 9b and 9c (see Supporting Information File 1, Figures S5 and S6). However, there is no such correlation in the 2D NOESY spectrum of the compound 9a (see Supporting Information File 1, Figure S4), which confirmed that the diamidoethylene bridge did not insert to the cavity of the pillar[5]arene to form [1] rotaxanes. Thus, the 2D NOESY spectra provided stronger evidence for the formation of novel bis[1] rotaxanes for the tris-pillar[5] arenes $9 \mathbf{c}-\mathbf{d}$ bearing longer than diaminopropylene diamido-bridges.

\section{Conclusion}

In summary, we have conveniently prepared several pillar[5]arene mono- and di(oxyalkoxy)benzoic acids and found that the chain of alkyl oxyalkoxybenzoate did not inserted to the cavity of pillar[5] arene. More importantly, a series of diamidobridged bis-pillar[5] arenes and tris-pillar[5]arenes were efficiently synthesized by catalyzed amidation reaction of pillar[5] arene mono- and di(oxybutoxy)benzoic acids with monoamide-functionalized pillar[5]arenes. On the basis of ${ }^{1} \mathrm{H}$ NMR and 2D NOESY spectra, we successfully concluded that the chains longer than diaminopropylene threaded into the one or two cavities of the pillar[5] arenes to form the unique [1] rotaxane and bis-[1] rotaxanes. This work not only provided a fundamental self-assembly of the mechanically interlocked molecules, but also developed the potential applications of pillar[5] arene in supramolecular chemistry. The design and construction of diverse mechanically interlocked molecules are underway in our laboratory.

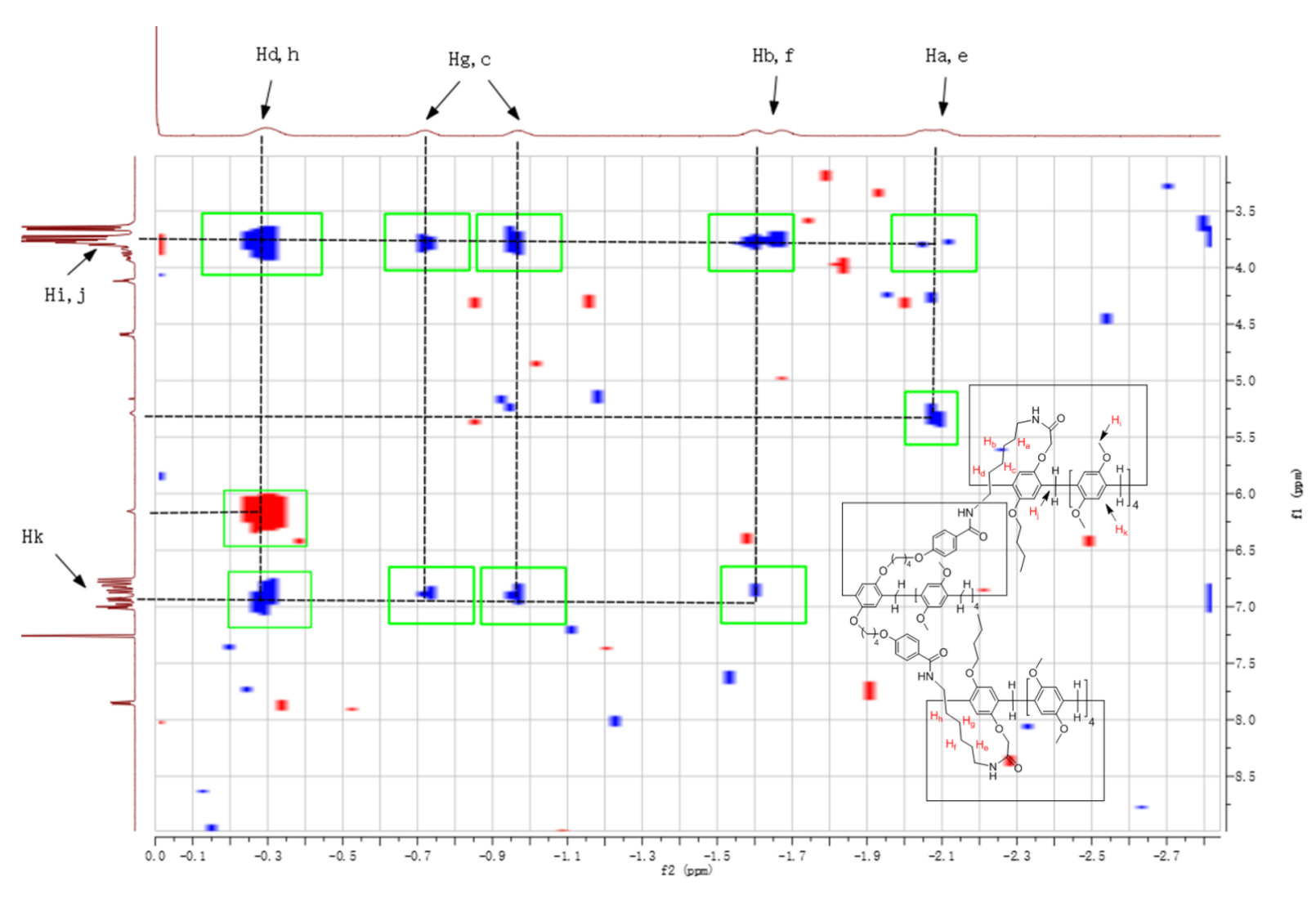

Figure 5: The 2D NOSEY spectra of tris-pillar[5]arene 9d. 


\section{Supporting Information}

Experimental procedures, analytical data, and copies of the ${ }^{1} \mathrm{H}$ and ${ }^{13} \mathrm{C}$ NMR spectra, HRMS spectra for all new products. Single crystal data for 2a (CCDC: 1837205), 2c (CCDC: 1837206), 2d (CCDC: 1837207), 2e (CCDC: 1837208), 2f (CCDC: 1837209) and 7 (CCDC: 1846692) have been deposited at the Cambridge Crystallographic Data Centre.

\section{Supporting Information File 1}

Experimental and analytical data.

[https://www.beilstein-journals.org/bjoc/content/ supplementary/1860-5397-14-142-S1.pdf]

\section{Acknowledgements}

We are grateful to the financial support by the National Natural Science Foundation of China (Grant No. 2137219) and the Priority Academic Program Development of Jiangsu Higher Education Institutions.

\section{References}

1. Wenz, G.; Han, B. H.; Müller, A. Chem. Rev. 2006, 106, 782-817. doi:10.1021/cr970027+

2. Erbas-Cakmak, S.; Leigh, D. A.; McTernan, C. T.; Nussbaumer, A. L. Chem. Rev. 2015, 115, 10081-10206.

doi:10.1021/acs.chemrev.5b00146

3. Fahrenbach, A. C.; Bruns, C. J.; Li, H.; Trabolsi, A.; Coskun, A.; Stoddart, J. F. Acc. Chem. Res. 2014, 47, 482-493. doi:10.1021/ar400161z

4. Bruns, C. J.; Stoddart, J. F. Acc. Chem. Res. 2014, 47, 2186-2199. doi:10.1021/ar500138u

5. Langton, M. J.; Beer, P. D. Acc. Chem. Res. 2014, 47, 1935-1949. doi:10.1021/ar500012a

6. Zhang, M.; Yan, X.; Huang, F.; Niu, Z.; Gibson, H. W. Acc. Chem. Res 2014, 47, 1995-2005. doi:10.1021/ar500046r

7. Qu, D.-H.; Wang, Q.-C.; Zhang, Q.-W.; Ma, X.; Tian, H. Chem. Rev. 2015, 115, 7543-7588. doi:10.1021/cr5006342

8. Xue, M.; Yang, Y.; Chi, X.; Yan, X.; Huang, F. Chem. Rev. 2015, 115, 7398-7501. doi:10.1021/cr5005869

9. Ogoshi, T.; Yamagishi, T.-a.; Nakamoto, Y. Chem. Rev. 2016, 116, 7937-8002. doi:10.1021/acs.chemrev.5b00765

10. Wang, Y.; Ping, G.; Li, C. Chem. Commun. 2016, 52, 9858-9872. doi:10.1039/C6CC03999E

11. Ma, X.; Tian, H. Chem. Soc. Rev. 2010, 39, 70-80. doi:10.1039/B901710K

12. Lewis, J. E. M.; Galli, M.; Goldup, S. M. Chem. Commun. 2017, 53, 298-312. doi:10.1039/C6CC07377H

13. Roberts, D. A.; Pilgrim, B. S.; Nitschke, J. R. Chem. Soc. Rev. 2018, 47, 626-644. doi:10.1039/C6CS00907G

14. Han, X.; Liu, G.; Liu, S. H.; Yin, J. Org. Biomol. Chem. 2016, 14, 10331-10351. doi:10.1039/C6OB01581F

15. Lewis, J. E. M.; Beer, P. D.; Loeb, S. J.; Goldup, S. M. Chem. Soc. Rev. 2017, 46, 2577-2591. doi:10.1039/C7CS00199A
16. Li, S.-H.; Zhang, H.-Y.; Xu, X.; Liu, Y. Nat. Commun. 2015, 6, No. 7590. doi:10.1038/ncomms8590

17. Chi, X.; Yu, G.; Shao, L.; Chen, J.; Huang, F. J. Am. Chem. Soc. 2016, 138, 3168-3174. doi:10.1021/jacs.5b13173

18. Eichstaedt, K.; Jaramillo-Garcia, J.; Leigh, D. A.; Marcos, V.; Pisano, S.; Singleton, T. A. J. Am. Chem. Soc. 2017, 139, 9376-9381. doi:10.1021/jacs.7b04955

19. De Bo, G.; Dolphijn, G.; McTernan, C. T.; Leigh, D. A. J. Am. Chem. Soc. 2017, 139, 8455-8457. doi:10.1021/jacs.7b05640

20. Wang, Y.; Sun, J.; Liu, Z.; Nassar, M. S.; Botros, Y. Y.; Stoddart, J. F. Chem. Sci. 2017, 8, 2562-2568. doi:10.1039/C6SC05035B

21. Hiratani, K.; Kaneyama, M.; Nagawa, Y.; Koyama, E.; Kanesato, M. J. Am. Chem. Soc. 2004, 126, 13568-13569. doi:10.1021/ja046929r

22. Ogawa, T.; Nakazono, K.; Aoki, D.; Uchida, S.; Takata, T. ACS Macro Lett. 2015, 4, 343-347. doi:10.1021/acsmacrolett.5b00067

23. Ogawa, T.; Usuki, N.; Nakazono, K.; Koyama, Y.; Takata, T. Chem. Commun. 2015, 51, 5606-5609. doi:10.1039/C4CC08982K

24. Xue, Z.; Mayer, M. F. J. Am. Chem. Soc. 2010, 132, 3274-3276. doi:10.1021/ja9077655

25. Waelés, P.; Clavel, C.; Fournel-Marotte, K.; Coutrot, F. Chem. Sci. 2015, 6, 4828-4836. doi:10.1039/C5SC01722J

26. Schröder, H. V.; Wollschläger, J. M.; Schalley, C. A. Chem. Commun. 2017, 53, 9218-9221. doi:10.1039/C7CC05259F

27. Li, H.; Zhang, H.; Zhang, Q.; Zhang, Q.-W.; Qu, D.-H. Org. Lett. 2012, 14, 5900-5903. doi:10.1021/ol302826g

28. Li, H.; Zhang, J.-N.; Zhou, W.; Zhang, H.; Zhang, Q.; Qu, D.-H.; Tian, H. Org. Lett. 2013, 15, 3070-3073. doi:10.1021/ol401251u

29. Li, H.; Li, X.; Agren, H.; Qu, D.-H. Org. Lett. 2014, 16, 4940-4943. doi:10.1021/ol502466x

30. Ma, X.; Qu, D.; Ji, F.; Wang, Q.; Zhu, L.; Xu, Y.; Tian, H. Chem. Commun. 2007, 1409-1411. doi:10.1039/b615900a

31. Ma, X.; Wang, Q.; Tian, H. Tetrahedron Lett. 2007, 48, 7112-7116. doi:10.1016/j.tetlet.2007.07.209

32. Yamauchi, K.; Miyawaki, A.; Takashima, Y.; Yamaguchi, H.; Harada, A. Org. Lett. 2010, 12, 1284-1286. doi:10.1021/ol1001736

33. Ogoshi, T.; Kanai, S.; Fujinami, S.; Yamagishi, T.-a.; Nakamoto, Y. J. Am. Chem. Soc. 2008, 130, 5022-5023. doi:10.1021/ja711260m

34. Cao, D.; Kou, Y.; Liang, J.; Chen, Z.; Wang, L.; Meier, H. Angew. Chem., Int. Ed. 2009, 48, 9721-9723. doi:10.1002/anie.200904765

35. Liu, Z.; Nalluri, S. K. M.; Stoddart, J. F. Chem. Soc. Rev. 2017, 46, 2459-2478. doi:10.1039/C7CS00185A

36. Zhang, H.; Strutt, N. L.; Stoll, R. S.; Li, H.; Zhu, Z.; Stoddart, J. F. Chem. Commun. 2011, 47, 11420-11422. doi:10.1039/c1cc14934b

37. Zhang, H.; Liu, Z.; Xin, F.; Hao, A. Chin. J. Org. Chem. 2012, 32, 219-229. doi:10.6023/cjoc1107141

38. Zhang, H.; Zhao, Y. Chem. - Eur. J. 2013, 19, 16862-16879. doi:10.1002/chem.201301635

39. Zhang, H.; Ma, X.; Nguyen, K. T.; Zhao, Y. ACS Nano 2013, 7, 7853-7863. doi:10.1021/nn402777x

40. Zhang, H.; Ma, X.; Guo, J.; Nguyen, K. T.; Zhang, Q.; Wang, X.-J.; Yan, H.; Zhu, L.; Zhao, Y. RSC Adv. 2013, 3, 368-371. doi:10.1039/C2RA22123C

41. Zhang, H.; Nguyen, K. T.; Ma, X.; Yan, H.; Guo, J.; Zhu, L.; Zhao, Y. Org. Biomol. Chem. 2013, 11, 2070-2074. doi:10.1039/c2ob27340c

42. Zhang, H.; Ma, X.; Nguyen, K. T.; Zeng, Y.; Tai, S.; Zhao, Y. ChemPlusChem 2014, 79, 462-469. doi:10.1002/cplu.201300408

43. Chen, H.; Fan, J.; Hu, X.; Ma, J.; Wang, S.; Li, J.; Yu, Y.; Jia, X.; Li, C. Chem. Sci. 2015, 6, 197-202. doi:10.1039/C4SC02422B 
44. Ma, J.; Meng, Q.; Hu, X.; Li, B.; Ma, S.; Hu, B.; Li, J.; Jia, X.; Li, C. Org. Lett. 2016, 18, 5740-5743. doi:10.1021/acs.orglett.6b03005

45. Sun, Y.; Fu, W.; Chen, C.; Wang, J.; Yao, Y. Chem. Commun. 2017, 53, 3725-3728. doi:10.1039/C7CC00291B

46. Li, B.; Meng, Z.; Li, Q.; Huang, X.; Kang, Z.; Dong, H.; Chen, J.; Sun, J.; Dong, Y.; Li, J.; Jia, X.; Sessler, J. L.; Meng, Q.; Li, C. Chem. Sci. 2017, 8, 4458-4464. doi:10.1039/C7SC01438D

47. Ping, G.; Wang, Y.; Shen, L.; Wang, Y.; Hu, X.; Chen, J.; Hu, B.; Cui, L.; Meng, Q.; Li, C. Chem. Commun. 2017, 53, 7381-7384. doi:10.1039/C7CC02799K

48. Ogoshi, T.; Demachi, K.; Kitajima, K.; Yamagishi, T.-a. Chem. Commun. 2011, 47, 7164-7166. doi:10.1039/c1cc12333e

49. Chen, Y.; Cao, D.; Wang, L.; He, M.; Zhou, L.; Schollmeyer, D.; Meier, H. Chem. - Eur. J. 2013, 19, 7064-7070. doi:10.1002/chem.201204628

50. Xia, B.; Xue, M. Chem. Commun. 2014, 50, 1021-1023. doi:10.1039/C3CC48014C

51. Ni, M.; Hu, X.-Y.; Jiang, J.; Wang, L. Chem. Commun. 2014, 50, 1317-1319. doi:10.1039/C3CC47823H

52. Guan, Y.; Liu, P.; Deng, C.; Ni, M.; Xiong, S.; Lin, C.; Hu, X.-Y.; Ma, J.; Wang, L. Org. Biomol. Chem. 2014, 12, 1079-1089. doi:10.1039/c3ob42044b

53. Wu, X.; Ni, M.; Xia, W.; Hu, X.-Y.; Wang, L. Org. Chem. Front. 2015, 2, 1013-1017. doi:10.1039/C5Q000159E

54. Wu, X.; Gao, L.; Sun, J.; Hu, X.-Y.; Wang, L. Chin. Chem. Lett. 2016, 27, 1655-1660. doi:10.1016/j.cclet.2016.05.004

55. Sun, C.-L.; Xu, J.-F.; Chen, Y.-Z.; Niu, L.-Y.; Wu, L.-Z.; Tung, C.-H.; Yang, Q.-Z. Chin. Chem. Lett. 2015, 26, 843-846. doi:10.1016/j.cclet.2015.05.030

56. Du, X.-S.; Wang, C.-Y.; Jia, Q.; Deng, R.; Tian, H.-S.; Zhang, H.-Y.; Meguellati, K.; Yang, Y.-W. Chem. Commun. 2017, 53, 5326-5329. doi:10.1039/C7CC02364B

57. Cheng, M.; Wang, Q.; Cao, Y.; Pan, Y.; Yang, Z.; Jiang, J.; Wang, L. Tetrahedron Lett. 2016, 57, 4133-4137. doi:10.1016/j.tetlet.2016.07.038

58. Han, Y.; Huo, G.-F.; Sun, J.; Xie, J.; Yan, C.-G.; Zhao, Y.; Wu, X.; Lin, C.; Wang, L. Sci. Rep. 2016, 6, No. 28748. doi:10.1038/srep28748

59. Huo, G.-F.; Han, Y.; Sun, J.; Yan, C.-G.

J. Inclusion Phenom. Macrocyclic Chem. 2016, 86, 231-240. doi:10.1007/s10847-016-0652-x

60. Han, Y.; Huo, G.-F.; Sun, J.; Yan, C.-G.; Lu, Y.; Lin, C.; Wang, L. Supramol. Chem. 2017, 29, 547-552. doi:10.1080/10610278.2017.1287367

61. Jiang, S.; Han, Y.; Sun, J.; Yan, C.-G. Tetrahedron 2017, 73, 5107-5114. doi:10.1016/j.tet.2017.07.001

62. Jiang, S.; Han, Y.; Zhao, L.-L.; Sun, J.; Yan, C.-G. Supramol. Chem. 2018, 30, 642-647. doi:10.1080/10610278.2018.1427238

63. Jiang, S.; Han, Y.; Cheng, M.; Sun, J.; Yan, C.-G.; Jiang, J.; Wang, L. New J. Chem. 2018, 42, 7603-7606. doi:10.1039/c7nj05192a

64. Yin, C.-B.; Han, Y.; Huo, G.-F.; Sun, J.; Yan, C.-G. Chin. Chem. Lett. 2017, 28, 431-436. doi:10.1016/j.cclet.2016.09.008

\section{License and Terms}

This is an Open Access article under the terms of the Creative Commons Attribution License

(http://creativecommons.org/licenses/by/4.0), which permits unrestricted use, distribution, and reproduction in any medium, provided the original work is properly cited.

The license is subject to the Beilstein Journal of Organic Chemistry terms and conditions:

(https://www.beilstein-journals.org/bjoc)

The definitive version of this article is the electronic one which can be found at:

doi:10.3762/bjoc. 14.142 